\title{
REVISTAS FEMININAS NOS SITES DE REDES SOCIAIS DIGITAIS: ANÁLISE DO CONTEÚDO PUBLICADO E ESTRATÉGIAS DE COMUNICA- ÇÃO
}

\author{
TAÍS STEFFENELLO GHISLENI \\ CENTRO UNIVERSITÁRIO FRANCISCANO \\ SANTA MARIA, RIO GRANDE DO SUL, BRASIL \\ TAISGHISLENI@YAHOO.COM.BR \\ LETÍCIA RODRIGUES MOREIRA \\ CENTRO UNIVERSITÁRIO FRANCISCANO \\ SANTA MARIA, RIO GRANDE DO SUL, BRASIL \\ LETICIAR_MOREIRA@YAHOO.COM.BR
}




\section{REVISTAS FEMININAS NOS SITES DE REDES SOCIAIS DIGITAIS: ANÁLISE DO CONTEÚDO PUBLICADO E ESTRATÉGIAS DE COMUNI- CAÇÃO}

Resumo: O presente artigo reflete a respeito de como as revistas femininas se apresentam e se comunicam com seu target, por meio do Twitter. Este estudo foi construído por meio das percepções de Sodré (2002) e Fausto Neto (2005), no que se refere à midiatização. O corpus de análise constituiu-se das revistas Nova Cosmopolitan e TPM, em uma semana composta, percebido pela análise de conteúdo, via tabela qualiquantitativa, como poderá ser observado.

Palavras-chave: Estratégias de Comunicação; Revistas Femininas; Twitter.

\section{REVISTAS LA MUJER EN REDES DIGITALES SITIOS: ANÁLISIS DE CONTENIDO ENVIADO Y ESTRATEGIAS DE COMUNICACIÓN}

Resumen: En este artículo se reflexiona sobre cómo las revistas femeninas se presentan y se comunican con su objetivo, a través de Twitter. Este estudio fue construido por la percepción de Sodré (2002) y Fausto Neto (2005) en materia de sociedad multimedia. El corpus análisis consistió en revistas cosmopolita y New TPM, en una semana compuesta percibida por análisis de contenido, a través de la mesa cuali-cuantitativa, como se puede observar.

Palabras clave: Estrategias de comunicación; Las revistas femeninas; Twitter.

\section{FEMININE MAGAZINES IN DIGITAL SOCIAL NETWORKING SITES: ANALYSIS OF PUBLISHED CONTENT AND COMMUNICATION STRA- TEGIES}

Abstract: This article reflects on how women's magazines present themselves and communicate with their target through Twitter. This study was constructed through the perceptions of Sodré (2002) and Fausto Neto (2005), regarding mediatization. The corpus of analysis consisted of the magazines Nova Cosmopolitan and TPM, in a composite week, perceived by the content analysis, via a quantitative table, as can be observed.

Keywords: Communication Strategies; Women's Magazines; Twitter. 


\section{INTRODUÇÃO}

A constante metamorfose das tecnologias vem trazendo transformações, também para a área da comunicação. O desenvolver destes processos gera diversas pesquisas tanto na recepção, quanto na transmissão dos discursos. No caso do presente trabalho tenta-se desvendar as estratégias utilizadas pelas marcas, nas mídias digitais, mais especificamente as revistas TPM e Nova Cosmopolitan, em seus perfis no Twitter. Além disso, também se objetiva mensurar suas publicações e o conteúdo destas, para observar até que ponto as semelhanças entre o público de interesse das marcas faz com que tenham seus conteúdos replicados, curtidos e comentados nas mídias sociais digitais.Ou seja,o presente estudo tem por objetivos identificar como dois perfis de revistas femininas, no Twitter, que buscam persuadir, basicamente, o mesmo público, abordam os mesmos temas, quais são suas estratégias, como os veículos tentam se relacionar com suas leitoras e qual a tendência do discurso utilizado.

Diante destes objetivos o estudo se estrutura em nove etapas, da seguinte forma, em seu primeiro momento será abordado as percepções de Sodré (2002) e Fausto Neto (2005) a respeito das transformações ocorridas nas relações comerciais e sociais com o desenvolver das tecnologias e suas utilizações - midiatização. Também no primeiro momento deste texto será exposto a idéia de estratégias de comunicação, sobre a visão de Saad (2008). Já no segundo momento do estudo serão apresentadas as características da nova ambiência em que se desenvolve as relações comunicacionais e a transformação ocorrida com os hábitos de consumo, perante a visão de Levy (1999) e de Karsaklian (2014), respectivamente.

Nas etapas seguintes são apresentados a definição de mídias digitais, segundo Recuero (2009) e a definição e histórico do Twitter, sobre a percepção de Strutzel (2015) também é abordada a definição de presença digital. Após a apresentação dos referenciais teóricos norteadores deste estudo a etapa seguinte será a apresentação dos objetos empíricos, os perfis das revistas femininas TPM e Nova Cosmopolitan, e em seguida é exposto a metodologia utilizada para se desenvolver a pesquisa. A penúltima fase é a análise dos dados colhidos, e a finalização se dá com as considerações finais, perante a descrição das etapas deste artigo dá-se início a exposição dos conceitos.

\section{MIDIATIZAÇÃO E ESTRATÉGIAS DE COMUNICAÇÃO}


Na percepção de Sodré "midiatização" refere-se a "tendência à "virtualização" ou telerrealização das relações humanas, presente na articulação do múltiplo funcionamento institucional e de determinadas pautas individuais de conduta com as tecnologias da comunicação" (2002, p. 21), com base nesta descrição pode-se considerar que a midiatização é o processo de apropriação dos fluxos comunicacionais institucionais e sócias pelo ambiente digital e tecnológico, caracterizando-se por um aumento nos fluxos de informação e uso das tecnologias, mediadas pelas ferramentas digitais.

Ainda de acordo com Sodré (2002), a

\begin{abstract}
"midiatização" é uma ordem de mediações socialmente realizadas no sentido da comunicação entendida como processo informacional, a reboque de organizações empresariais e com ênfase num tipo particular de interação - a que poderíamos chamar de "tecnointeração" -, caracterizada por uma espécie de prótese tecnológica e mercadológica da realidade sensível, denominada medium. Trata de dispositivo cultural historicamente emergente no momento em que o processo da comunicação é técnica e industrialmente redefinido pela informação, isto é, por um regime posto quase que exclusivamente a serviço da lei estrutural do valor, o capital, e que constitui propriamente uma nova tecnologia societal (e não uma neutra "tecnologia da inteligência") [...]" (SODRÉ, 2002, p.21/22).
\end{abstract}

Nos estudos de Fausto Neto (2005), a "sociedade midiatizada" seria uma "combinatória de conhecimentos e operações estruturadas nas formas de tecnologias e de linguagens através das quais se produzem novas formas de interações" (p. 10). Partindo destas duas percepções pode-se considerar que o movimento pelo qual faz as empresas penetram no ambiente digital, tentando estabelecer relações comerciais com seus clientes e perpetuarem em seu cotidiano, não deixa de ser uma estratégia comunicacional, contudo é o processo de midiatização da sociedade, em que tem por objetivo a manutenção dos discursos e o desenvolvimento do capital financeiro e social, no ambiente digital e tecnológico.

Mas o entendimento de estratégias faz parte deste fluxo e neste caso, as estratégias comunicacionais são como escolhas realizadas a partir de várias possibilidades midiáticas, e isso faz com que as organizações precisem se ajustar ao contexto observando novas circunstâncias e reorganizando suas práticas midiáticas. $\mathrm{O}$ ambiente proporcionado pela internet funciona como um espaço de fluxos' da comunicação e se mostra adequado para o uso de 
estratégias, especialmente para ampliar a visibilidade institucional e criar relacionamentos.

É importante que os princípios da estratégia sejam abordados de forma criteriosa para que o desempenho organizacional seja satisfatório e a comunicação possa ser instituída como fluxo e, não, reduzida a um sistema de informações (BALDISSERA, 2001). Saad buscou em Manovitch (1992) três vetores de orientação de uma estratégia baseada em mudanças tecnológicas:

- medidas rotineiras que busquem elevar a qualidade e a produtividade;- projetos inovadores para ter acesso a tecnologias de base, internalizar tecnologias determinantes ou acompanhar tecnologias emergentes;- ações empreendedoras para enfrentar rupturas tecnológicas imprevistas, promovendo alianças estratégicas ou investindo em novas unidades de negócio (SAAD, 2008, p. 42).

A partir da indicação dos vetores mencionados, um novo fator passou a ser levado em consideração, que é "a influência da relação da mídia com a sociedade e o seu papel formador e transformador da opinião da própria sociedade" (SAAD, 2008, p.42). E para dar conta desta indicação, o ecossistema articula os meios de comunicação, incluindo as práticas de recepção, produção e circulação do processo comunicativo e considera tanto as práticas, as estratégias comunicacionais ${ }^{2}$ e a estrutura vigente.

Sendo assim, da mesma forma que as empresas se adaptam aos novos processos comunicacionais e conduzem a midiatização, os consumidores também se modificam, adaptando-se aos novos canais e quantidades de informações disponíveis para seu consumo em ambientes dinâmicos e em constante mutação, logo se pode considerar que o comportamento do consumidor e seu espaço de consumo alteraram-se como será abordado no próximo etapa deste estudo.

\section{CIBERCULTURA E COMPORTAMENTO DO CONSUMIDOR}

A internet já tem bem mais de trinta anos, contudo nos últimos dezesseis anos, ou seja, a partir do ano 2000 , ela tem tomado um papel mais atuante no cotidiano da sociedade trazendo facilidades e complexidades às relações humanas tanto nas interpessoais, quanto nas comercias e intelectuais, nestas pode-se destacar as relações de consumo, estudadas por várias áreas 
do conhecimento. Sendo assim nesta fase, da pesquisa, serão apresentadas algumas teorias e considerações que abordam estas alterações nos espaços e nos hábitos de consumo, tais como o conceito de cibercultura e ciberespaço e o desenvolvimento do processo de compra/consumo.

O desenvolvimento dos processos ocasiona uma reação, a adaptação, a transformação dos hábitos, que são necessários, mas de difícil mensuração em longo prazo, pois os fluxos ocorrem de forma dinâmica e efêmera. Estas considerações podem ser entendidas como parte de um processo comunicacional, social e técnico - a cibercultura, comprovadas nos estudos de Levy (1999, p.27) no qual afirma que "o digital, fluido, em constante mutação, [...][é] desprovido de qualquer essência estável. Mas, justamente, a velocidade de transformação é em si mesma uma constante - paradoxal - da cibercultura", esta segundo ele (1999, p. 247) expressa "uma mutação fundamental da própria essência da cultura". Perante isto as transformações culturais, tratam também de transformações nos hábitos e costumes de uma sociedade o que acarreta alterações profundas em seus padrões de consumo. Os processos de consumo se alteraram, estão levando em consideração outros aspectos antes inimagináveis como, por exemplo, as redes sociais digitais e a co-produção dos consumidores. Estes aspectos nos levam a outro conceito de Levy (1999, p. 32), o ciberespaço estruturado pelo "novo espaço de comunicação, de sociabilidade, de organização e de transação, mas também novo mercado da informação e do conhecimento".

Estes dois processos resultam na formação dos "novos consumidores", que são aqueles "mais capazes de escolher não só o que compram [consomem], como também como e onde essas compras são feitas [...]" de acordo com Lewis e Bridges (2004, p.2). Mas antes de se consumar o ato de consumo/compra há um processo que considera fatores externos e internos, e que percorrem as motivações, as necessidades, os desejos, as preferências, o autoconceito ${ }^{3}$, os freios, as percepções ${ }^{4}$ e as atitudes. Neste processo Karsaklian (2014) expõe que as motivações ${ }^{5}$ dão início ao processo de compra/consumo, quando há a identificação de um desequilíbrio psicológico, no que se refere a uma necessidade, que é a "[...] discrepância suficiente entre um estado desejado ou preferido de estar e o estado atual" (KARSAKLIAN, 2004, p. 36). Desenvolvendo o conceito de "necessidades" se chega até a Teoria de Maslow (KARSAKLIAN, 2014, p. 34-35), na qual as necessidades humanas são organizadas em prioridades e hierarquias escalonadas em quatro níveis, necessidades fisiológicas, de segurança, de perti- 
nência e afeto, de estima e de auto-realização.

Desta forma para alcançar cada nível é necessário estar inserido em "grupos de referência”, que segundo Karsaklian (p. 101, 2014) são “toda agregação de interação pessoal que influência as atitudes e os comportamentos de um indivíduo [...]”. Esta influência gerada dentro do grupo pelo indivíduo é baseada em sua posição (conjunto de direitos e deveres do indivíduo no grupo), status (valor diferencial de cada posição dentro do grupo) e função (comportamento esperado) (KARSAKLIAN, 2014, p. 102) no grupo.

A alteração nos estilos de vida realocou as posições, funções e status dos indivíduos dentro dos grupos de referência. Dentro destes grupos há vários indivíduos, e entre estes os influenciadores, que também se modificaram, por exemplo, na utilização de outros canais de comunicação (pois hoje eles estão nos canais de vídeo, como o YouTube e nas redes sociais digitais) e também no seu conteúdo (eles demonstram as funcionalidades do produto, expondo suas fraquezas e qualidades, considerando que muitos destes não são pagos pelas marcas), tornaram-se especializados para conquistarem visibilidade e credibilidade e posteriormente seguidores, em muitos casos. Neste sentido Lewis e Bridges (2004) destacam duas categorias de influenciadores, os cool hunters e os conhecedores, considerando que cada um destes exercerá um nível de influência sobre seus conteúdos especializados e de acordo com as estratégias empregadas. Os Cool hunters referem-se aqueles indivíduos que sabem o que acontecerá e o que nunca acontecerá no mundo das tendências e ainda fornecem de tudo aos fabricantes (LEWIS e BRIDGES, 2004, p. 83), se pode considerá-los como os caçadores de tendências, que poderão apresentá-las para as empresas ou para os consumidores antes da massificação do consumo, por exemplo. Já os conhecedores são divididos em da comunidade, profissionais, e ainda em celebridades conhecedoras e fanáticos. Os primeiros dizem respeito àquelas pessoas mais persuasivas, "é aquele que não recebe nada [...] em sua área auto selecionada de especialidade, ele se mantém bem-informado quanto às últimas tendências e modas [...]" (LEWIS e BRIDGES, 2004, p.86), os segundo "são indivíduos cuja atividade profissional ou qualificações lhes dão autoridade ou experiência genuína em uma área específica” (LEWIS e BRIDGES, 2004, p.87); os autores ainda destacam os fanáticos, aqueles que são altamente especializados em determinado tema; e as celebridades conhecedoras, estas segundo Lewise Bridges (2004) eram mais eficazes para 
os "velhos consumidores", pois hoje os "novos consumidores", com todo acesso a informação que possuem entendem que estas são pagas para anunciar e podem nem conhecer o produto/serviço em seu cotidiano, por exemplo.

Diante deste contexto observa-se que os conhecedores podem influenciar os "novos consumidores", mas também são influenciados por estes para que possam seguir em audiência e expansão no ciberespaço, por meio de suas estratégias e conteúdos direcionados em cada mídia utilizada, principalmente as mídias digitais nas quais se pode expor-se para grupos de interesse específicos de seu conteúdo. Com isso na próxima fase deste estudo serão expostos conceitos e definições de "mídias sociais digitais", para que se possa compreender mais uma etapa do processo de comunicação entre empresas e os "novos consumidores".

\title{
4 MÍdIAS SOCIAIS E A PRESENÇA DIGITAL
}

Neste tópico será exposto o conceito de mídias digitais, suas funcionalidades e aplicações dentro da comunicação de uma empresa ou marca. Neste sentido tem-se que o ambiente digital se apropriou de algumas formas de convívio da sociedade, dando origem aos "sites de redes sociais", por exemplo, mas também as mídias tradicionais foram adaptadas, os jornais e revistas necessitaram introduzir-se e adaptar-se ao meio digital para continuar suas relações comerciais com seus consumidores/usuários, considerações que podem ser reafirmadas nos estudos de Fausto Neto (2005), quando menciona que os

\begin{abstract}
meios de comunicação não permanecem subordinados a outras práticas, enquanto mediações, uma vez que vão assumindo uma posição de centralidade na dinâmica social, [...] Ou seja, seus papéis são transformados, uma vez que, da condição de suportes passam a ocupar "uma centralidade na vida cotidiana, como fonte de informação e de entretenimento, como fonte de construções de imaginários" (FAUTONETO, 2005, p.8/9).
\end{abstract}

Esta centralização dos meios no cotidiano dos indivíduos se dá, entre outros mecanismos, através dos "sites de redes sociais" e mídias digitais, de Raquel Recuero, a fim de esclarecer estes conceitos.

Para Recuero (2009, p.102) os sites de redes sociais são "toda a ferramentas que for utilizada de modo a permitir que se expressem as redes sociais 
suportadas por ela [...] são os espaços utilizados para a expressão das redes sociais na internet", pode-se considerá-las como a replicação (pela continuidade de relações afetivas e profissionais na web) e a ampliação (pelo processo de globalização) das redes sociais não digitais para o ambiente virtual. Já Strutzel (2015), percebe as "redes sociais de massa" (Twitter e Facebook), como disseminadores dos mais diversos temas de conteúdos, representantes dos indivíduos mais ativos, com alto poder de segmentação de público, ou seja, excelentes canais de relacionamento.

Para ela a grande diferença entre os sites de redes sociais e os outros meios de comunicação via internet é "o modo como permitem a visibilidade e a articulação das redes sociais, a manutenção dos laços sociais estabelecidos no espaço off-line" (2009, p.103), definição que integra o Twitter como um site de rede social. Mas esta ferramenta ainda é categorizada de forma mais especifica como "sites de redes sociais apropriados" -"aqueles sistemas que não eram, originalmente, voltados para mostrar redes sociais, mas que são apropriados pelos atores com este fim" (2009, p.104). Neste caso ele dá a visibilidade necessária ao conteúdo proposto pelas revistas, de forma a gerar interesse pelas marcas e demais ferramentas digitais, assim como seus produtos e serviços (revistas impressas, sites, eventos, por exemplo), além disso faz a manutenção dos laços por meio da possibilidade de respostas, comentários e curtidas, nos perfis das revistas, mas também desenvolve o papel de publicitar a marca, seu posicionamento e discurso, trabalhando como uma mídia. Neste sentido pode-se destacar como objetivo dos "sites de redes sociais", de pessoas jurídicas a captação das informações sobre seus seguidores/usuários, mas também estabelecer um relacionamento para medir sua receptividade.

O processo de midiatização, ocasionou o ciberespaço e este apropriou-se das mídias sociais e as introduziu no meio digital resultando na "presença digital", na qual se estabelecem os novos pontos de contato entre empresa e consumidor, de acordo com Tércio Strutzel (2015). Logo as mídias ditas tradicionais não são mais suficientes para chamar a atenção dos consumidores, pois os "novos consumidores" buscam mais informações e estão expostos a várias mídias e conteúdos distintos simultaneamente, com isso quanto mais qualificado o conteúdo maior será a possibilidade de determinada marca, chamar a atenção e iniciar um relacionamento com este consumidor, por exemplo. Tanto as redes sociais, quanto os aplicativos e mídias digitais se organizam em torno das informações cedidas involunta- 
riamente e voluntariamente por seus usuários, como destacamos, no texto que apresenta o Twitter.

Sendo assim têm-se que a presença digital "designa as redes de relacionamento baseadas na confiança, cooperação e inovação que são desenvolvidas pelos indivíduos dentro e fora de organizações" (GÁRCIA apud STRUTZEL, 2015, p.46), neste sentido pode-se considerar que a presença digital faz uso dos grupos de referência citados por Karsaklian, (2014), nos quais há a troca de informações e experiências resultando em novas percepções, por exemplo. Para organizar o processo da presença digital Strutzel (2015) estabelece quatro níveis, a saber:

Existência: [...] ser atuante na web, compartilhando conteúdo relevante ao público-alvo e desenvolvendo pontos de contato entre o consumidor e a marca [...];

Atração: [...] produção de conteúdo, o qual além de ser relevante e ter qualidade, precisa ter uma frequência de exposição adequada, mantendo o equilíbrio para não saturar a audiência e nem passar despercebido [...];

Relacionamento: momento [...] delicado, [...] relacionamento estável com a audiência conquistada [...] é imprescindível um acompanhamento muito próximo do feedback para cada ação e conteúdo publicado ou compartilhado [...] o monitoramento constante o administrador consegue perceber alterações sensíveis nos níveis de leitura e visualização do conteúdo [...];

Engajamento: "é o nível máximo de relacionamento entre a marca e o consumidor, onde este acompanha ativamente o conteúdo publicado[...]. (STRUTZEL, 2015, p.89-91).

Logo a presença digital, movimenta e gera o capital social para a empresa, e esta deve ter entre seus objetivos - gerar conteúdo relevante para permanecer em destaque em meio a tantas fontes de informação que a web possui. A seguir quando será apresentado o Twitter como ferramenta de comunicação, seus termos e utilidades.

\subsection{Twitter}

Twitter significa “[...] pequenas quantidades de informação e, também, [...] pios de aves" ${ }^{\prime}$, certamente este meio de comunicação tem em seu nome o reflexo de sua funcionalidade, já que o micro-blogging e rede social digital possibilita a publicação de até 140 caracteres e mais recentemente a publicação de até $15 \mathrm{MB}$ em arquivos audiovisuais, como gifs ${ }^{7}$ e vídeos ${ }^{8}$, além 
de ter, no ano de 2015, iniciado a comercialização dos tweets promovidos9. Antes destinado ao compartilhamento de informações pessoais diretas (o que você está fazendo?), hoje o Twitter (que foi criado no ano de 2006) funciona mais como uma ferramenta de comunicação entre empresa e cliente, e como um periódico dinâmico e objetivo (o que está acontecendo?) divulgando os acontecimentos da sociedade (ou círculo de relações sociais) e em alguns casos sendo a principal forma de comunicação e divulgação de processos políticos de países africanos (primavera árabe) no ano de 2010, por exemplo.

Seu canal de acesso é o endereço <https://Twitter.com/?lang=pt-br>, nele o usuário poderá criar uma conta, fazer configurações que permitam este, encontrar outros perfis e ser encontrado, acessando pelo aplicativo ou pelo site, no móbile e no desktop. Para melhor descrever a ferramenta será apresentado, a seguir, algumas definições, elaboradas pela própria plataforma e apresentadas em seu site ${ }^{10}$, que são utilizadas no decorrer deste estudo, tais como tweet, tweetar, curtir, menção e retweet.

Tweet "pode conter fotos, vídeos, links e texto com até 140 caracteres";

Tweetar "ato de enviar um Tweet. Os Tweets são mostrados em timelines do Twitter ou são inseridos em websites e blogs";

Curtir "Toque no ícone de coração para curtir um Tweet, e o autor vai saber que você gostou";

Menção “Mencionar outros usuários no seu Tweet incluindo o sinal @ seguido diretamente pelo nome de usuário é chamado de "menção". Também se refere aos Tweets em que o seu @nomedeusuário foi incluído";

Retweet "Tweet que você encaminha para seus seguidores é conhecido como um Retweet. Geralmente usado para transmitir notícias ou outras descobertas valiosas no Twitter, os Retweets sempre mantêm a atribuição original”;(TWITTER, 2016, online).

Além de ser utilizado por pessoas físicas o Twitter, nos últimos anos tem criado funcionalidades cada vez maiores para atrair pessoas jurídicas. Entre estas estão os tweets promovidos, já mencionados, o Twitter Analytics, que se utiliza das informações capturadas e cedidas pelos seus usuários para mensurar, por exemplo, os hábitos de consumo, o alcance, o engajamento, a fidelidade e até mesmo quem são os influenciadores destes usuários; e o Twitter Ads, utiliado em conjunto com a ferramenta anterior. Sendo assim o Twitter é "rede social digital apropriada" (RECUERO, 2015), que coleta da- 
dos dos seus usuários e os utiliza em gráficos de aplicativos "para proporcionar uma experiência mais personalizada” (TWITTER, 2016) em seu ambiente e também comercializar estas informações com empresas interessadas em aumentar e especializar sua presença digital. Na próxima etapa deste estudo serão apresentados os perfis da revista Nova Cosmopolitam, da revista TPM, no Twitter.

\section{OBJETOS EMPÍRICOS}

Neste trabalho os perfis analisados no Twitter são da revista Cosmopolitan Brasil, que foi escolhida como objeto empírico, pois na pesquisa dos cem títulos pagos com maior circulação, publicado em 2015, da Associação Nacional de Editores de Revistas, ela está em $13^{\circ}$ lugar ${ }^{11}$ geral e para a faixa etária de seu público ela é a $1^{a}$ revista com maior circulação. Já a revista TPM foi escolhida por se apresentar de forma diferenciada dos demais títulos femininos tanto no conteúdo (abordando temas polêmicos, como o aborto), quanto no layout de seu impresso e sítio.

A revista TPM é da plataforma de comunicação UOL, é uma segmentação da revista TRIP (título direcionada ao público masculino) como podemos perceber em seu slogan "TPM - TRIP para mulheres: é outra conversa”. Foi criada em 2001, com periodicidade mensal e circulação nacional, esta diz tratar de assuntos do cotidiano feminino, mas com "leveza e inteligência”, diferenciando-se dos títulos femininos nacionais convencionais, como se pode perceber no seguinte trecho "[...] a TPM traz os temas e debates mais instigantes do universo feminino por meio de matérias que expressam o dia a dia das mulheres que não se viam refletidas nas páginas das revistas femininas convencionais". Outro fato que pode ser observado em sua apresentação no mídia kit é que: "[...] algumas matérias questionam os padrões impostos pela sociedade às mulheres, como a busca pelo corpo perfeito ou uma família "margarina", [...]".

Quanto ao disseminação de conteúdo da revista TPM não está somente no impresso e no digital, além da revista impressa, da fanpage, do perfil no Instagram e do Twitter e mais recentemente no Snapchat, a marca também tem produções audiovisuais e o projeto Casa TPM. Este conteúdo é direcionado para, também segundo o mídia kit do selo, $92 \%$ de mulheres, $88 \%$ com ensino superior completo e $69 \%$ entre os 26 e 45 anos, seu site conta com um tempo médio de navegação de $05 \mathrm{~min}$ e 600 mil pageviews $\mathrm{s}^{12} / \mathrm{mês}$, em seu Twitter, ferramenta de estudo do presente trabalho, no início desta pesqui- 
sa, em 29 de maio deste ano, contava com mais de 78 mil seguidores e ao seu término, em 16 de julho do mesmo ano, aumentou para 80 mil.

Figura $\mathrm{N}^{\circ}$ 1: Capa do perfil da Revista TPM

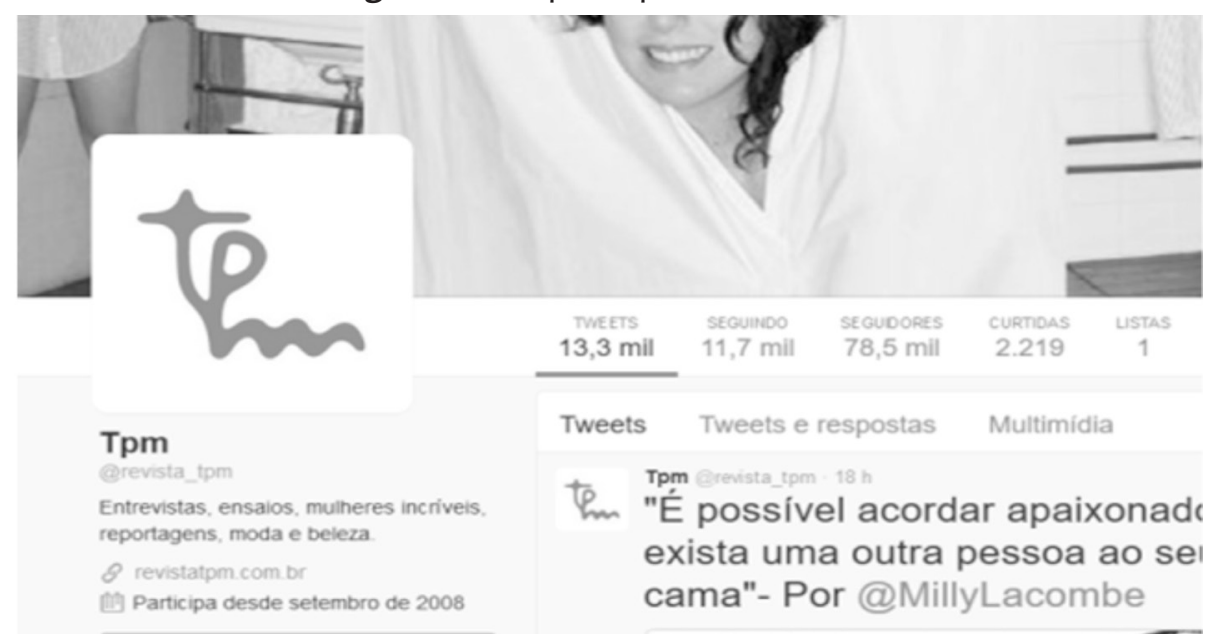

Fonte: Twitter TPM ${ }^{13}$

Já a revista Nova, que no último ano reformulou sua estrutura e trocou seu título para Cosmopolitan Brasil temos uma revista de periodicidade mensal e circulação nacional, presente no Brasil desde a década de 1970, na grade da Editora Abril. De acordo com o próprio título a reformulação da publicação ocorreu para obter maior unidade com o selo internacional, como se pode perceber nos seguintes trechos da carta da diretora de redação Juliana De Mari: “[...] como outras 60 edições publicadas em mais de 70 países e 32 línguas mundo afora. [...]" e "aproveitamos a troca de nome para reforçar nossos pilares editoriais, como a crença de que praticar o espírito de sisterhood (mulheres apoiando outras mulheres) [...]”. Estas questões apresentadas na carta são reafirmadas pelos tweets publicados em seu perfil e pelo slogan da marca que é "COSMOPOLITAN - Divertida, ousada e muito feminina".

Também como na revista TPM o conteúdo da revista Cosmopolitan Brasil não está somente no impresso, além da revista impressa, da fanpage, do perfil no Instagram e do Twitter e mais recentemente no Snapchat, a marca também faz parte do portal $M$ de Mulher (que engloba, além da marca Cosmopolitan, outros títulos femininos da editora Abril) com conteúdo audiovisual, infográficos e muitas matérias direcionadas para o público feminino e brasileiro, de acordo com o site. O público que consome este conteúdo é $86 \%$ feminino, $73 \%$ com idade entre 20 e 49 anos, $52,7 \%$ da classe "B" e $27,8 \%$ da classe " $C$ ", seu site conta com um tempo médio de navegação de 04min27s e mais de 31.500 mil pageviews, em seu Twitter, também ferramenta de estudo deste trabalho, no início desta pesquisa, em 29 de maio 
deste ano, contava com mais de 46 mil seguidores, e ao seu término, em 16 de julho do mesmo ano, aumentou para 46,5 mil.

Figura $\mathbf{N}^{\circ}$ 2: Capa do perfil da Revista Nova Cosmopolitan

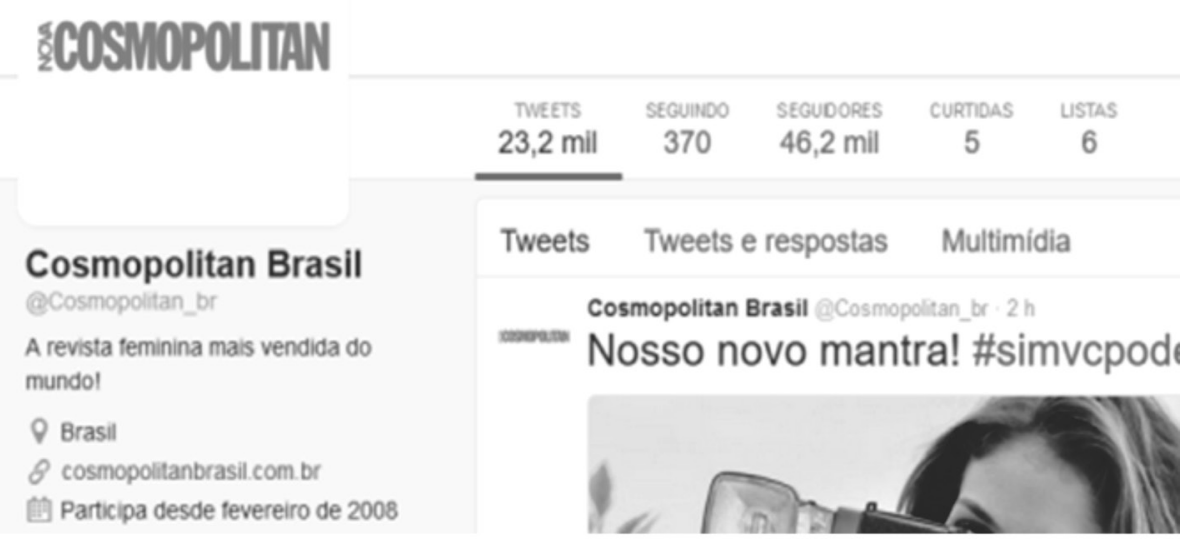

Fonte: Twitter Revista Nova Cosmopolitan ${ }^{14}$

Considerando os perfis apresentados e observando as informações contidas na pesquisa brasileira de mídia 2015, que apresenta os hábitos de consumo de mídia no Brasil como, por exemplo, $67 \%$ dos consumidores acessam a internet para se divertir e se informar, a maior frequência de acesso fica entre as 19 horas e 21 horas, que $83 \%$ das pessoas da faixa etária compreendida entre os 26 e 45 anos usam a internet sete dias por semana e destes $37 \%$ são mulheres, podemos perceber que o público das revistas estudas está presente no universo digital de forma massiva e aberto para o consumo de bens tangíveis e intangíveis.

A partir destas informações percebe-se o espaço existente no ambiente digital, oportunizando a captura de informações dos consumidores, a produção colaborativa de conteúdo (entre empresa e consumidor), além da produção de conteúdo específico para cada perfil de consumidor. Neste sentido é que se desenvolve este artigo e a partir deste momento passa-se ao detalhamento do estudo.

\subsection{Método de estudo dos objetos empíricos}

Aqui será explicado os métodos utilizados para analisar os perfis das revistas TPM e Nova Cosmopolitan, ou seja, a definição das categorias consideradas, o período e o método de captura, e também o tipo de pesquisa. Por isso classificou-se esta pesquisa quanto a sua natureza, como qualiquantitativa e quanto aos objetivos, exploratória. Para captar e analisar os dados colhidos foi elaborada uma tabela que compreende tanto os dados qualitativos, tanto os quantitativos dos perfis, como poderá ser observado no 
decorrer deste texto.

Quanto ao aspecto qualitativo de pesquisas qualiquantitativas considera-se que o objetivo da amostra "é de produzir informações aprofundadas e ilustrativas: seja pequena ou grande, o que importa é que ela seja capaz de produzir novas [e relevantes] informações"(DESLAURIERS, apud ENGEL e SILVEIRA, 2009, p. 32)

Nas percepções de Engele Silveira (2009) as pesquisas qualitativas tem como características

[...] a objetivação do fenômeno; hierarquização das ações de descrever, compreender, explicar, precisão das relações entre o global e o local em determinado fenômeno; observância das diferenças entre o mundo social e o mundo natural; respeito ao caráter interativo entre os objetivos buscados pelos investigadores, suas orientações teóricas e seus dados empíricos; [...] (ENGEL \& SILVEIRA, 2009, p. 32).

Logo o aspecto qualitativo da presente pesquisa refere-se ao esclarecimento das formas de comunicação entre meios tradicionais inseridos no ambiente digital via ferramenta Twitter, além da hierarquização, exposição e explicação das estratégias utilizadas nesta ferramenta pelos perfis das revistas femininas. Quanto aos aspectos quantitativos Engele Silveira (2009) o percebem como objetivo, por recorrerem "à linguagem matemática para descrever as causas de um fenômeno, as relações entre variáveis, etc" (FONSECA, 2002, p. 20 apud ENGEL e SILVEIRA, 2009, p. 33). Na presente pesquisa os aspectos quantitativos se apresentam por meio da quantificação das curtidas, comentários e retweets (que são os compartilhamentos), com isso poderá ser percebido de forma objetiva (por meio de gráficos) quais as estratégias de publicação, medir a receptividade destas publicações e quais os temas e categorias mais publicados pela revista TPM e pela revista Nova Cosmopolitan.

Classificando esta pesquisa com base em seus objetivos, percebe-a como "exploratória", pois de acordo com Gil (2007) apud Engele Silveira (2009) este tipo de pesquisa tem por finalidade "proporcionar maior familiaridade com o problema, com vistas a torná-lo mais explícito ou a construir hipóteses". Neste sentido o presente estudo tem em seus objetivos a tentativa de expor a comunicação institucional, em ambiente digital, na forma de disseminação de conteúdo, pelas ferramentas e aplicativos da plataforma digital Twitter. 
O método utilizado foi a análise de conteúdo, ou seja,

um conjunto de técnicas de análise de comunicação visando obter, por procedimentos sistemáticos e objetivos de descrição do conteúdo das mensagens, indicadores (quantitativos ou não) que permitam a inferência de conhecimentos relativos às condições de produção/recepção destas mensagens. (BARDIN, 1977, p.42).

Considerando esta definição a análise do presente estudo foi organizada em observação e captação dos tweets nos perfis, tematização e categorização do conteúdo e confrontação e interpretação dos dados. Desta forma a primeira etapa foi construída pela captura dos tweets dos perfis das revistas TPM e Cosmopolitan Brasil, no período compreendido entre 29/05/2016 a 16/07/2016, na forma de semanas compostas ${ }^{15}$. No segundo momento o conteúdo dos tweets foi sendo classificados de acordo com seu conteúdo e receptividade, ou seja, qual o tema e subtema abordados, presença do autor, presença de imagens ou audiovisuais, presença de links externos e que fossem direcionados para as outras plataformas digitais do veículo (principalmente o site das revistas) e quantificação das curtidas, retweets e compartilhamentos, se utilizando da tabela matriz apresentada na tabela 1.

Tabela $\mathrm{N}^{\circ}$ 1: Tabela Matriz

\begin{tabular}{|l|l|}
\hline \multicolumn{2}{|c|}{ Estratégias de comunicação com o target e análise do discurso destas } \\
\hline \multicolumn{2}{|c|}{ TíTULO ANÁLISADO } \\
\hline Mídia Social Digital: Twitter & Período de análise: $29 / 05$ à 16/07 \\
\hline Método de captura: "print e copia do link do tweet" & Método de periodização: semana composta \\
\hline Período da semana composta / dia da semana & Posição de publicação / título da publicação \\
\hline Categoria/Tema & \\
\hline Presença de texto & \\
\hline Presença de imagem & \\
\hline Presença de \# & \\
\hline Link externo & \\
\hline Link para a revista & \\
\hline Presença de audiovisual & \\
\hline $\mathrm{N}^{\circ}$ de Curtidas & \\
\hline $\mathrm{N}^{\circ}$ de Retweets & \\
\hline $\mathrm{N}^{\circ}$ de Comentários & \\
\hline Turno da publicação & \\
\hline Identificação do Autor & \\
\hline
\end{tabular}

Fonte: elaboração própria.

A tabela matriz também traz a "identificação do autor" do texto que deu origem ao tweet, a identificação do "título analisado", neste caso o Twitter da revista TPM e o da revista Nova Cosmopolitan; o título da própria matriz; a identificação da ferramenta analisada, o período, o dia da sema- 
na e o período da semana composta; o turno a publicação, bem como as posições das publicações sua categoria e tema. Quanto às categorias, pela prévia análise do conteúdo das revistas, optou-se por destacar a categoria "comportamento" e a "entretenimento", na qual estas referem-se a conteúdos relacionados com "cinema, séries, literatura”, "sexo”, “celebridades”, “beleza”, “moda”, “relacionamentos”, “animais”, “motivação”, “humor”, "variedades", "turismo" e "tecnologia”. Já a categoria "comportamento" refere-se a conteúdos relacionados à sociedade, ao gênero e representação, violência, racismo, celebridades, relacionamento, saúde, beleza e questões internacionais.

Após a categorização dos tweets foram analisadas as características presentes para tentar identificar qual o tipo de discurso apresentado, quais as estratégias de comunicação mais presentes, para que ao final se identifique as semelhanças e diferenças entre dois veículos direcionados para o mesmo público, na mesma plataforma digital, que será apresentada na etapa seguinte - a análise.

\section{A ANÁLISE}

A partir dos conceitos de cibercultura e ciberespaço, do processo que envolve o ato de consumo e da evolução e constante transformação dos consumidores é que se desenvolve a análise, dos perfis das revistas NovaCosmopolitan e TPM, a seguir. De acordo com o relato exposto na metodologia, entre os dias 29/05/2016 e 16/07/2016 foram capturados, pelo método semana composta, 11 tweets da revista TPM, enquanto que a revista Nova Cosmopolita tweetou 121 vezes, estes eram tweetados entre a 01 hora da manhã e às 23 horas e aqueles eram tweetados no período da tarde. A publicação dos tweets da revista Nova Cosmopolitan pelo seu acompanhamento é possível supor que estes foram agendados, já as publicações da revista TPM foram em diferentes horários e em quantidades menores, pode-se supor que há um social media atuando. Neste sentido a média de tweets apresentada é também bastante significativa, pois a revista TPM tem uma média de 1,57 tweets a cada sete dias e a revista Nova Cosmopolita tem média de 17,28 tweets, contudo esta média inclui também os 6,62\% de conteúdo replicado que o perfil apresentou, nestes sete dias de observação, enquanto que o perfil do Twitter da revista TPM não apresentou nenhuma replicação, fatos que indicam a importância dada a quantidade de publicações em detrimento ao ineditismo (este aspecto é considerado em relação ao próprio, 
já que no momento comunicacional e no segmento de atuação da revista o conteúdo inédito é efêmero) e relevância do conteúdo no cotidiano dos seguidores.

Quanto ao conteúdo publicado observou-se que os temas coletivos, ligados aos gêneros (principalmente o feminino) e que abordam temas que visam esclarecer e melhor o convívio em sociedade são destacados nas publicações do Twitter da revista TPM, reafirmando o seu posicionamento: “[...] a Tpm traz os temas e debates mais instigantes do universo feminino por meio de matérias que expressam o dia a dia das mulheres que não se viam refletidas nas páginas das revistas femininas convencionais" (TPM, 2016), (já mencionado na apresentação dos perfis).

A porcentagem identificada, nos temas, é de $82 \%$ para as publicações referentes a comportamentos sociais e apenas $18 \%$ relacionados ao entretenimento, nesse sentido as categorias mais expressivas publicadas são as seguintes: relacionamento e celebridades;no entanto a categoria "relacionamento" está muito mais relacionada a questão do indivíduo lidar com fato de que é necessário momentos de solidão (segundo Milly Lacombe, a autora do texto $)^{16}$ e com os aspectos negativos da maternidade ${ }^{17}$, do que com as questões ligadas com as dinâmicas dos relacionamentos entre casais, como se pode observar no gráfico 1 a seguir.

Gráfico No 1: TPM - Categorias

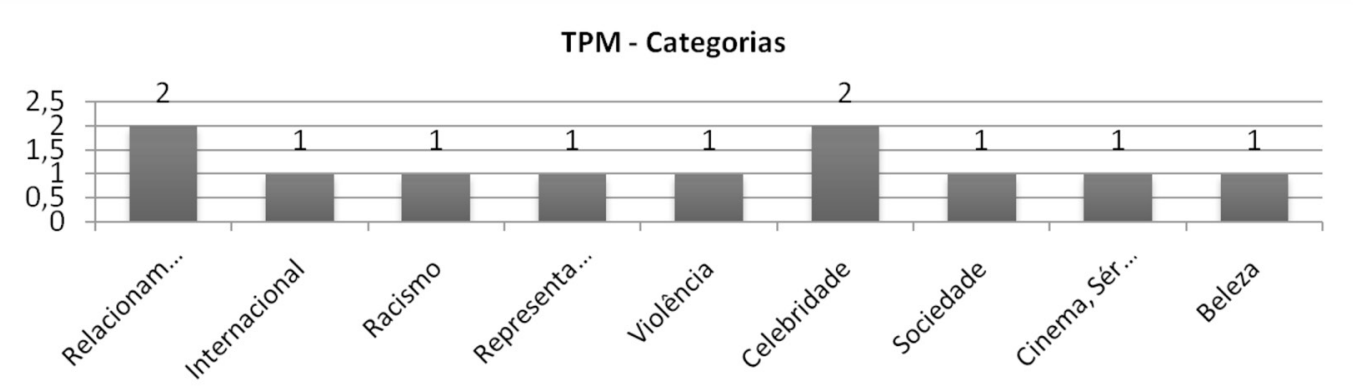

Fonte: elaboração própria.

Já na categoria "celebridades", as publicações são a respeito de Clarice Falcão ${ }^{18}$ e Juçara Marçal ${ }^{19}$, a primeira é humorista, atriz e cantora, com grande audiência na plataforma audiovisual digital - YouTube, via Porta dos Fundos; e a segunda, também é cantora, além de ser ativista social e integrante do grupo MetáMetá20. Diante destas breves apresentações pode-se observar que as "celebridades" com espaço nas publicações da revista, são aquelas que estão relativamente distantes das mídias tradicionais e dos grandes veículos de comunicação. Contudo os tweets da revista Nova Cosmopolitan abordam temas individuais, que visam desenvolver o seguidor/usuário 
nos níveis estabelecidos pela teoria de Maslow, principalmente nos níveis de pertinência e afeto, de estima e de auto-realização, pois seu conteúdo é voltado para exposição de orientações para desenvolver relacionamentos amorosos e várias formas de se obter prazer físico e sexual, como se pode acompanhar no gráfico 2.

No que se refere à publicação dos temas a porcentagem identificada entre "comportamento" e "entretenimento", foi de 31\% para 69\%, respectivamente. Sendo assim a contraposição de conteúdo entre as revistas femininas se apresenta de forma clara e objetiva, pois nesta, em contrapartida ao da revista TPM, há a predominância de conteúdos relacionados ao entretenimento (69\%) e a individualidade. E dentro do tema "entretenimento", há a predominância de cinco categorias: "celebridades", "sexo”, "beleza”, "cinema, séries e literatura" e "humor", respectivamente; indicado no gráfico 2.

Gráfico $\mathbf{N}^{\circ}$ 2: Nova Cosmopolitan - Categorias

Nova Cosmopolitan - Categorias
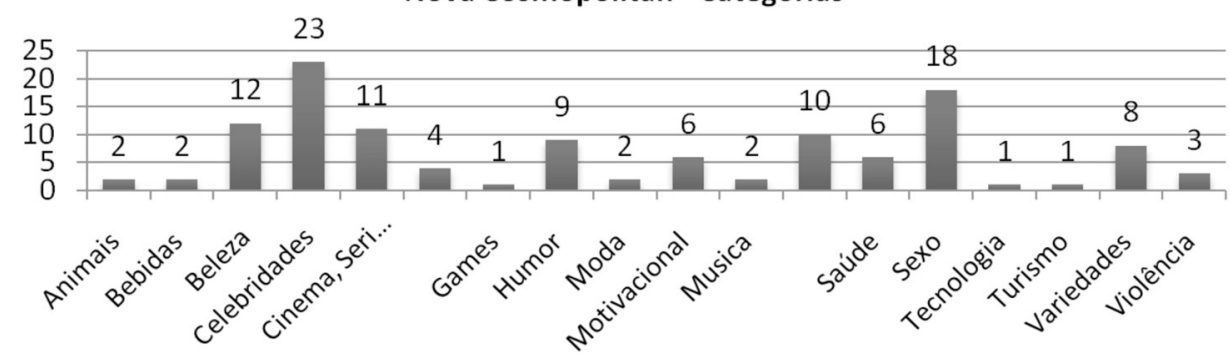

Fonte: elaboração própria.

Ainda sobre as categorias percebe-se que as "celebridades" com expressiva exposição são aquelas que têm visibilidade, também nas mídias tradicionais como TV, tais como Cauã Reymond e Duquesa Kate e sua família. Já a categoria "sexo" refere-se a posições no ato sexual, na maior parte de suas publicações; considerando a categoria "beleza", esta faz referência a cosméticos, técnicas de maquiagem, cortes de cabelo, conteúdos nestas esferas.Quanto a "cinema, séries e literatura" faz referência, bem como o título já diz, a personagens femininas de filmes, a casais famosos das séries de TV e de filmes, reestreias de sérias da TV por assinatura, lançamentos de livros de conteúdo adultos; e quanto à categoria "humor" são expostos os "cards" com situações do cotidiano abordadas com humor, por exemplo, a figura 3 e 4 . 

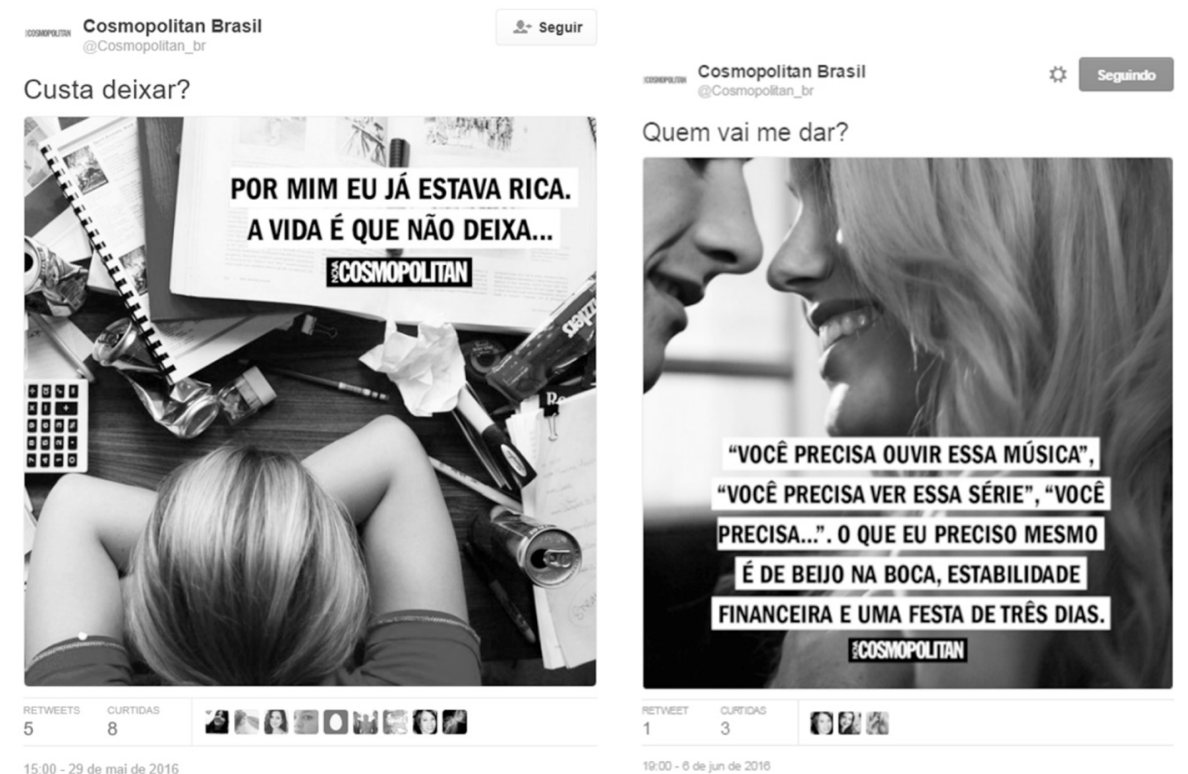

Fonte: Twitter Nova Cosmopolitan, 2016

Também é interessante destacar as publicações com mensagens motivacionais, que correspondem a $5 \%$ das publicações, apresentadas em forma de "cards", por exemplo as figuras 5 e 6, a seguir. Nessas observa-se o emprego da \#simvcpode, como um marcador de mensagem de apoio a mudanças nas vidas de suas leitoras, reprodução de discursos de jovens ativistas dos direitos femininos e a reafirmação do posicionamento "sisterhood" (já mencionado), que expõe a necessidade e o movimento cultural de assistência e incentivo entre as mulheres.

Figura $^{22} \mathrm{~N}^{\circ} 5$ e 6: Cards - entretenimento/motivacional
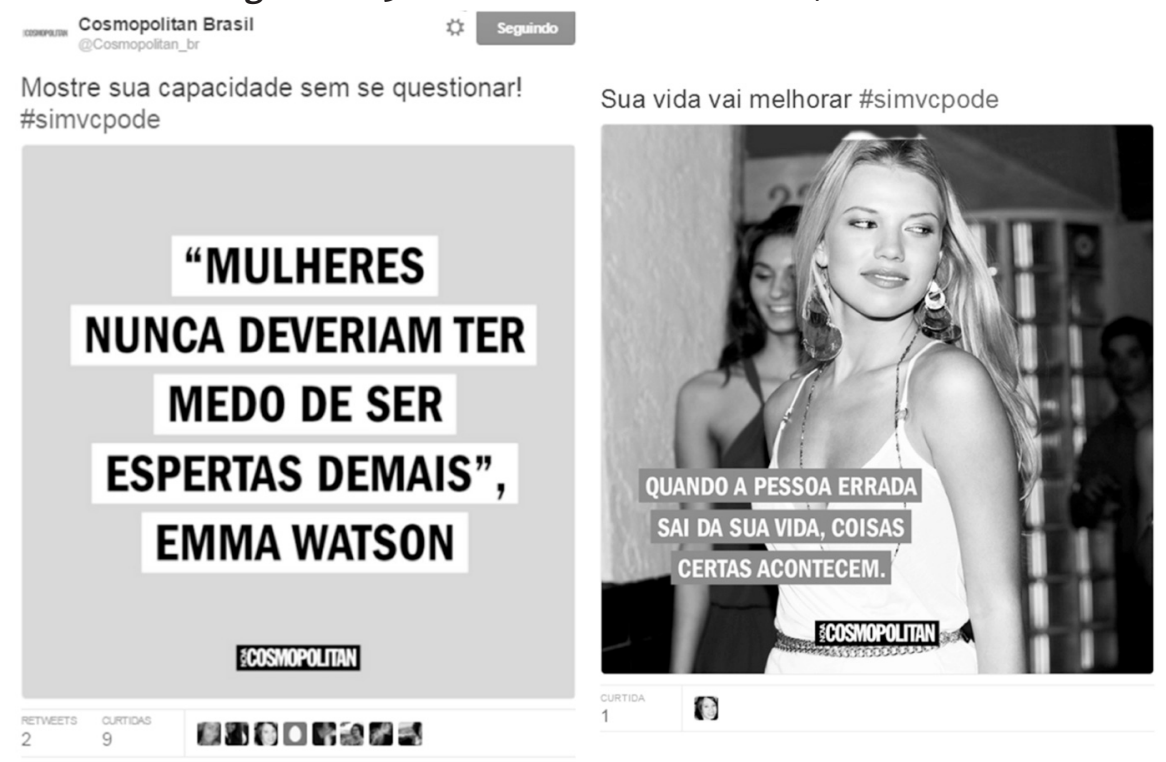

Fonte: Twitter Nova Cosmopolitan

Quanto as curtidas, retweets e comentários observou-se no perfil da revista, que todos os 11 tweets publicados tiveram pelo menos duas formas de 
interação, ou seja, ou eles eram curtidos e retweetados, ou eram retweetados e comentados e em alguns casos eles eram curtidos, compartilhados e comentados, totalizando 183 interações. Destas 2\% foram comentários, 24\% retweets e $74 \%$ foram curtidas.

Dentro destas interações as categorias e temas que se destacaram nos comentários foram "celebridade" e "relacionamento", sendo que o primeiro foi o tweet sobre Juçara Marçal e o segundo de autoria de Milly Lacombe, uma das colaboradoras da revista. E dentro dos $82 \%$ de conteúdo com a temática de comportamento as categorias mais curtidas foram respectivamente relacionamento, celebridade, beleza, e racismo, como podem ser observadas no gráfico a seguir.

Gráfico ํㅜㄴ: TPM - Curtidas por categoria

TPM - Curtidas por categorias

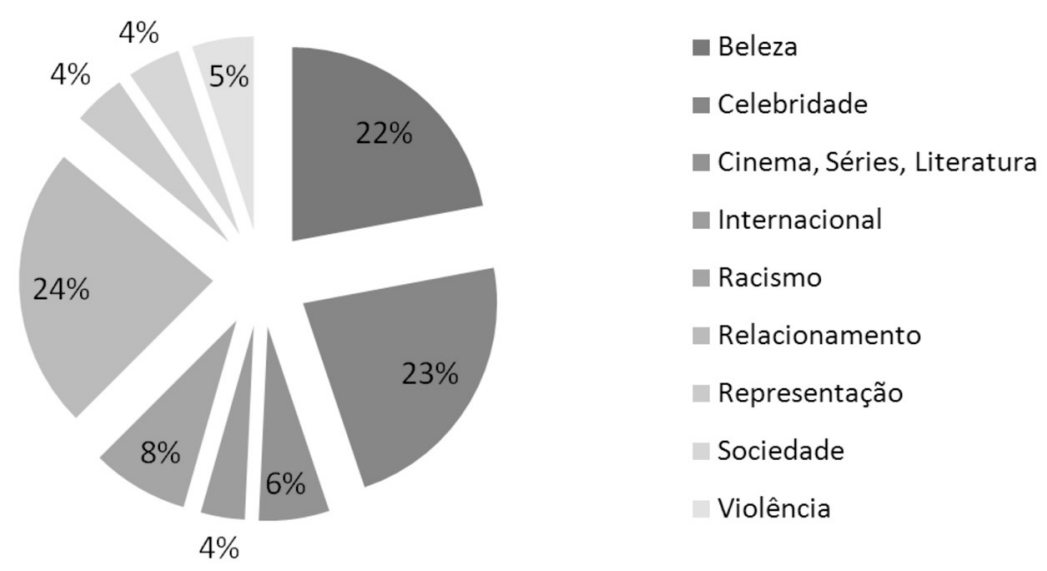

Fonte: Elaboração própria

Considerando que as publicações relativas a relacionamentos, a primeira refere-se à necessidade de algumas pessoas estarem sempre em um relacionamento e a segunda trata do relacionamento das mães com suas maternidades; as publicações categorizadas como celebridade, referem-se às cantoras Juçara Marçal e Clarice Falcão, como já mencionados; e a publicação com $22 \%$ de curtidas refere-se à notícia amplamente divulgada nos meios, sobre a cantora Alicia Keys ${ }^{23}$ que anunciou que reduziria o uso de cosméticos, principalmente maquiagem em contraposição a "ditadura da beleza", este pronunciamento também foi publicado no perfil da revista Nova Cosmopolitan e está entre os tweets com maior interação como será exposto no decorrer do texto. Quanto aos retweets o gráfico (4) do perfil da revista TPM ficou da seguinte forma: 


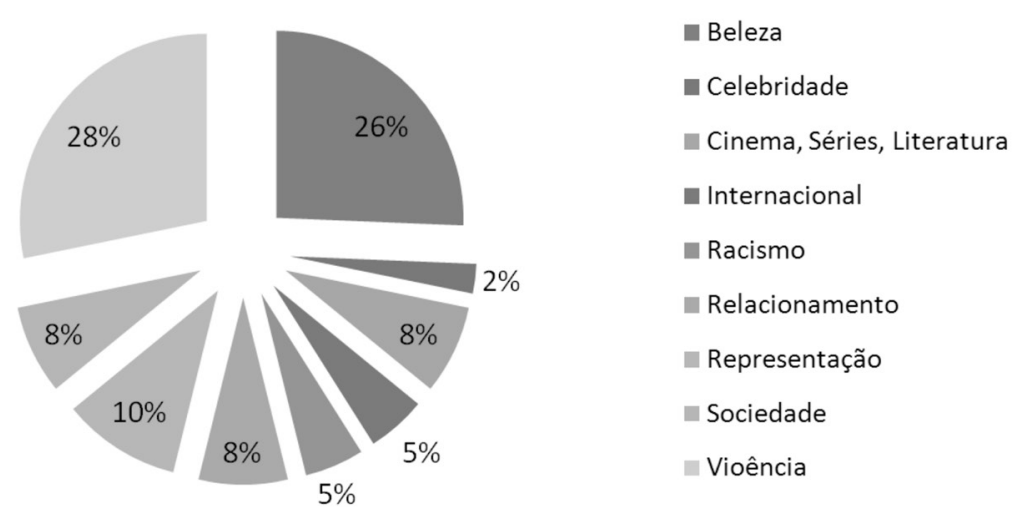

Fonte: Elaboração própria

Foi possível perceber que os conteúdos retweetados diferem-se um pouco aos mais curtidos, pois a categoria em segundo lugar é "violência"24, e esta publicação referiu-se a discussão sobre o assédio sofrido por jornalistas mulheres, escrito por Nina Lemos, outra colaboradora da revista.

No perfil da revista Nova Cosmopolitan, as interações percebidas foram curtidas e retweets, não havendo comentários dos seguidores nas publicações, também foi identificado na análise das publicações que $17 \%$ das interações foram retweets e $83 \%$ foram curtidas.

As $83 \%$ de publicações curtidas compreendiam todas as categorias, mas as cinco categorias mais curtidas foram celebridades, humor e sexo, motivação e cinema, séries e literatura, dados que se aproximam das porcentagens encontradas no gráfico 5, que expõe da publicação das categorias no perfil da Nova Cosmopolitan.

Gráfico $N^{\circ}$ 5: Nova Cosmopolitan - Curtidas por categoria

Nova Cosmopolitan - Curtidas por categorias
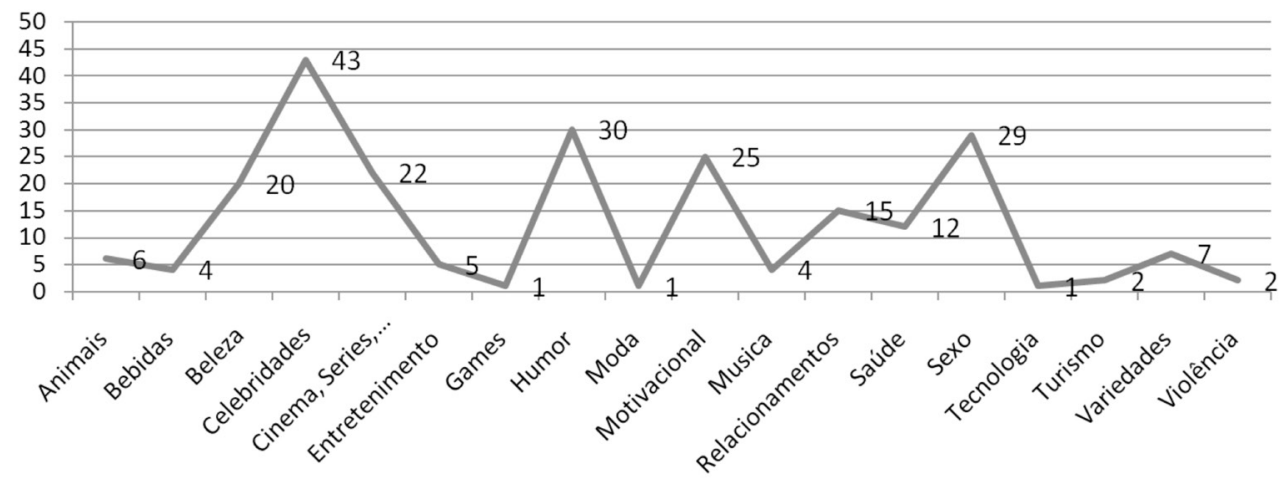

Fonte: Elaboração própria

Em relação ao gráfico que apresenta a porcentagem dos retweets por categoria observa-se que aquelas categorias mais curtidas não necessaria- 
mente são as mais retweetadas, como demonstra o gráfico 6:

Gráfico № 6: Nova Cosmopolitan - Curtidas por categoria

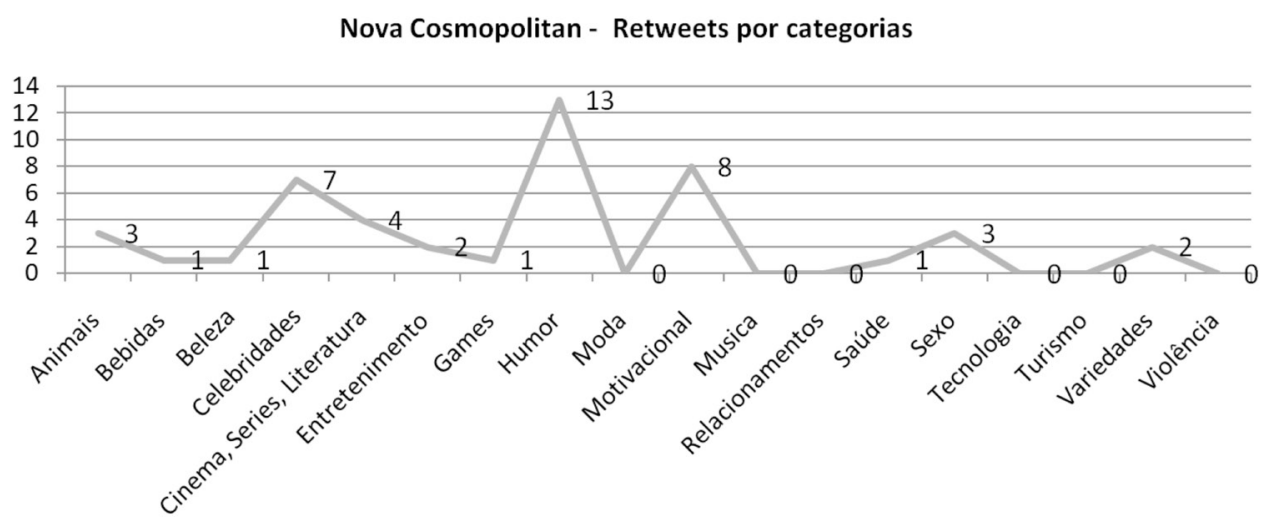

Fonte: Elaboração própria

Pois a categoria "humor", que tem 13\% das curtidas das publicações, no gráfico anterior ocupa o primeiro lugar neste gráfico, com 28\%; e a "motivacional" que tem $11 \%$ das curtidas, aumenta sua porcentagem para $17 \%$ dos retweets, enquanto que "celebridades" de 19\% de curtidas passa para 15\% de retweets, revelando que os seguidores consideram o humor passível de compartilhamento em detrimento as publicações sobre celebridades.

O presente estudo pode ser base para muitas outras indagações, como por exemplo, quem são os seguidores que curtem, compartilham e comentam estas publicações, mas aqui destaca-se somente a figura de Sara Caceres (@SaraCaceresB), esta pode ser considerada como uma conhecedora ou profissional, ou de comunidade, além de uma influenciadora, já que a maior parte das publicações que foram curtidas no período analisado ela era um dos indivíduos participantes.Tal forma de participação não foi observada nas publicações da TPM, por isso pode-se considerar que este perfil é um integrante da equipe de mídia do veículo. Portanto observou-se nos perfis das revistas que apesar do público de interesse ser muito próximo, as estratégias e conteúdo publicado são bem distintos, focando em temas e categorias semelhantes, mas conduzidas para esferas de relacionamento diferentes. Na etapa final deste estudo será apresentada algumas considerações relevantes para o melhor entendimento das distinções e semelhanças entre os perfis das revistas femininas.

\section{CONSIDERAÇÕES FINAIS}

Neste momento do texto será retomado seus objetivos e feito algumas considerações conclusivas a respeito dos perfis expostos, inicia-se com a 
identificação dos públicos. Como pode ser observar no sexto item deste trabalho os targets tanto da revista TPM, quanto da revista Nova Cosmopolitan são predominantemente femininos, tem também a mesma faixa etária, entre os 20 e 45 anos e a mesma escolaridade, além disso consomem a internet sete dias por semana, na sua maioria como meio de informação e entretenimento, neste sentido percebe-se a transformação tanto dos hábitos de consumo, quanto do ambiente de consumo. Estes dois movimentos socioculturais e tecnológicos reafirmam tanto o pensamento de "sociedade midiatizada" de Fausto Neto (2005, p.10), citado no segundo tópico deste artigo, como a alteração nos estilos de vida percebidos por Karsaklian (2014, p.132) e a Teoria de Maslow, também apresentada por esta autora. Pois as leitoras identificadas como target dos perfis das revistas estudas podem ser inseridas a partir do terceiro nível (necessidade de pertinência e afeto) até o topo da pirâmide (necessidade de auto-realização) percepção resultada da análise dos dados disponibilizados pelas mídias, pela pesquisa de consumo de mídias no Brasil e pelo conteúdo dos tweets das revistas; e a alteração no estilo de vida é percebida pela dualidade no ambiente de consumo, antes exclusiva do off-line e atualmente dividida entre este e o on-line, entre tantas outras formas de consumo.

Quanto às estratégias, e considerando o ambiente de consumo que se apresenta atualmente, pode-se identificar a presença digital como uma estratégia comunicacional. Esta presença se dá pelos perfis em vários sites de redes sociais digitais, como por exemplo, o Facebook, o Instagram, seu próprio sítio e o Twitter, base deste estudo. Mais precisamente quanto a presença digital dos perfis estudados, no Twitter, se identifica a existência das revistas femininas desde 2008, a Nova Cosmopolitan desde fevereiro e a TPM desde setembro. Quanto à atração pode-se considerar que as revistas mantêm estratégias distintas de atração, pois a TPM é voltada para conteúdos coletivos (como já mencionado) e a Nova Cosmopolitam é direcionada para conteúdos individuais, a primeira se utiliza de imagens, textos e vídeos, além de identificar o autor de alguns textos; a segunda se fixa em imagens e textos, além de não identificar os autores, posicionando seu conteúdo como editorial. No que se refere aos relacionamentos de forma geral pode-se se observar que a revista TPM mantém mais seguidores do que a Nova Cosmopolitam, mesmo com essa tendo um número maior de publicações.E por último têm-se o nível de engajamento, aquele em que o usuário/consumidor se apropria do conteúdo da empresa/marca, percebe-se que apesar 
do perfil da revista TPM ter menos publicações há maior engajamento entre os seguidores. Estas considerações serão retomadas na análise dos tweets para melhor identificar as estratégias de comunicação presentes nas publicações.

Outra questão são os horários e as frequências de publicação das revistas, o perfil da TPM faz publicações na parte da tarde e em média dois por dia, já o perfil da Nova Cosmopolitan faz publicações o dia inteiro, tendo em média quinze tweets por dia, esta alta frequência não reflete um alto engajamento com o conteúdo publicado, como pode se perceber nos gráficos apresentados. A revista TPM tem menos publicações, mas recebe, proporcionalmente, mais curtidas, retweets e comentários, além de ter mais seguidores que a revista Nova Cosmopolitan, no Twitter, além do tempo empregado nas páginas ser levemente menor, como já exposto.

No âmbito de se relacionarem com suas leitoras, tanto a TPM, quanto a Nova Cosmopolitan se deparam com um "novo mercado de informação e conhecimento", segundo Levy (1999, p.32) o ciberespaço, no qual a relevância do conteúdo, a abertura do meio para que seus leitores também possam ser co-produtores de conteúdo e os grupos de referência e dentro destes os influenciadores ditam o quão próximo o relacionamento entre o meio e seu usuário será prospero. A relevância do conteúdo no cotidiano dos consumidores ditará a probabilidade do mesmo ser propagado pelos influenciadores dos grupos de referência, neste sentido pode-se concluir que a relevância percebida nas publicações da TPM é maior do que na Nova Cosmopolitan, já que seu conteúdo é mais propagado; uma questão que deveria ser melhor observada pelo perfil da Nova Cosmopolitan, se as pessoas leem, porque elas não retweetam, mas esta é uma questão para outro estudo, com isso uma das possibilidades é o discurso/conteúdo das publicações, que será demonstrado a seguir.

Como já dito, neste artigo a relevância do conteúdo para o cotidiano do leitor é muito importante para que haja engajamento, nesta percepção a tendência do discurso utilizado, também é considerada. Os temas individuais e genéricos abordados pela Nova Cosmopolitan e os temas coletivos e específicos abordados pela TPM, são complementares, mas como estão em veículos distintos afetam leitores distintos, ou seja, apesar de terem a mesma faixa etária, a mesma escolaridade e a mesma classe social as mulheres que leem a as duas revistas podem ser pessoas diferentes. Por exemplo, na Nova Cosmopolitan a necessidade de unidade no discurso com os títulos 
mundiais, faz com suas publicações, em alguns casos, sejam replicações das revistas Cosmopolitan, de outros países, fato que pode não traduzir o cotidiano das consumidoras brasileiras. Neste aspecto os temas e as categorias até podem ser considerados os mesmos, mas o discurso das revistas são distintos, e direcionados para esferas complementares do cotidiano, pois o relacionamento individual que trata a revista Nova Cosmopolitan, interfere no relacionamento coletivo que aborda a revista TPM, por exemplo, mas também buscam persuadir, basicamente, o mesmo público, com visões díspar da sociedade. Portanto, os perfis das revistas possibilitam leituras relevantes em fases distintas do cotidiano de seus consumidores, as estratégias de comunicação, se o objetivo for o aumento dos seguidores, na revista TPM está em conformidade com seu posicionamento, contudo o da Nova Cosmopolitan pode ser revisto e alterado, principalmente na frequência e no conteúdo das publicações, movimentos acessíveis já que a ferramenta de comunicação Twitter possibilita pesquisas sobre seus usuários, com informações especificas, ocasionando comunicações mais direcionadas, por exemplo. 
CADERNOS DE COMUNICAÇÃO

UNIVERSIDADE FEDERAL DE SANTA MARIA

\section{REFERÊNCIAS}

ASSOCIAÇÃO Nacional de Editoras de Revistas. FACT BOOK.<http://aner.org.br/wp-content/uploads/2014/05/Factbook_2015_Site-FINAL.pdf>Acessoem 06/06/2016.

BALDISSERA, Rudimar. Estratégia, comunicação e relações públicas. Anais do XXIV Congresso Brasileiro de Comunicação. Campo Grande/ MS, Setembro de 2001, p.1-11. Disponível em: <http://www.portal-rp.com.br/bibliotecavirtual/relacoespublicas/teoriaseconceitos/0148.pdf> Acesso em 7 ago. 2014.

BARDIN, Laurence. Análise de conteúdo. Lisboa: Edições 70, 1977.

EDITORA Abril. Nova agora é Cosmopolitan e você é parte desta mudança. <http:// mdemulher.abril.com.br/estilo-de-vida/cosmopolitan-brasil/nova-agora-e-cosmopolitan-e-voce-e-parte-desta-mudanca>. Acesso em 05/06/2016, às 16h e 20 min.

EDITORAAbril. Marcas e Plataformas. 2016 <http://publiabril.abril.com.br/marcas/cosmopolitan>. Acesso em 01/06/2016, às 19horas.

INFOMONEY. Abril anuncia reestruturação e fecha revistas Alfa, Bravo, Gloss e Lola. <http://www.infomoney.com.br/negocios/grandes-empresas/noticia/2894692/abril-anuncia-reestruturacao-fecha-revistas-alfa-bravo-gloss-lola>. Acesso em 05/06/2016.

INTERNET - Hábitos dos usuários brasileiros. 2014. <http://dotgroup.com.br/wp-content/uploads/2014/05/INFO_3-01-12.jpg>.

KARSAKLIAN, Eliane. Comportamento do consumidor. 2 ed. São Paulo. Atlas. 2014.

LEVY, Pierre. Cibercultura. São Paulo. Ed 34. 1999.

LEWIS, Dr. David e Bridger, Darren. A Alma do consumidor. 2004. São Paulo. M. Books do Brasil Editora Ltda.

FAUTO NETO, Antônio. Midiatização - Prática social, prática de sentido. Texto rascunho circulação interna PPG-Com. São Leopoldo-RS. 2005.

GERHARDT, Tatiana Engel e TOLFO Silveira, Denise. (Orgs.) Métodos de pesquisa. Porto Alegre. Editora da UFRGS. 2009.<http://www.ufrgs.br/cursopgdr/downloadsSerie/derad005.pdf $>$. Acesso em 04 ago. 2016.

PLATAFORMA TPM. <http://www.tripeditora.com.br/comercial/>. Acesso em 25/06/2016.

MÍDIA Kit Trip e TPM. <http://www.tripeditora.com.br/wp-content/uploads/2012/03/Midia-Kit-TRIP-e-TPM.pdf>. Acesso em 25/04/2016.

RECUERO, Raquel. Redes sociais na internet. Porto Alegre. Sulina, 2009.

SAAD, Elizabeth. Estratégias 2.0 para a mídia digital: internet, informação e comunicação. 2.ed. São Paulo: SENAC, 2008.

BRASIL. Secretaria de Comunicação Social da Presidência da República. Pesquisa brasileira de mídia 2015. <http://www.secom.gov.br/atuacao/pesquisa/lista-de-pesquisas-quantitativas-e-qualitativas-de-contratos-atuais/pesquisa-brasileira-de-midia-pbm-2015. pdf>. Acesso em 07/06/2016.

SODRÉ, Muniz. Antropológica do Espelho: uma teoria da comunicação linear e em rede. Petrópolis -RJ. Editora Vozes. 2002. 
CADERNOS DE COMUNICAÇÃO

UNIVERSIDADE FEDERAL DE SANTA MARIA

STRUTZEL, Tércio. Presença digital: estratégias eficazes para posicionar sua marca pessoal ou corporativa na web. Rio de Janeiro. Alta Books. 2015.

TWITTER. O glossário do Twitter. 2016. <https://support.Twitter.com/articles/364620\#>. Acessoem 14 julh 2016.

TWITTER. Twitter Analytics. 2016. <https://business.Twitter.com/pt/analytics.html>. Acesso em 16 julh 2016.

WIKIPÉDIA. Cosmopolitan (Brasil). <https://pt.wikipedia.org/wiki/Cosmopolitan_(Brasil)>. Acesso em 28/06/2016.

\section{ENDNOTES}

1 A noção de "fluxo" torna possível identificar o papel vinculador da publicidade com o mundo social, explorando seu processo, suas práticas, a forma de seu discurso (PIEDRAS; JACKS, 2006).

2 "As estratégias comunicacionais são o modo como os emissores/receptores constroem e dispõem efeitos de sentido na cadeia de comunicação” (BALDISSERA, 2001, p.3).

3 "conceito que o consumidor tem de si ou que gostaria de ter" (KARSAKLIN, p.23/24, 2014).

4 "processo dinâmico pelo qual aquele que percebe atribui um significado a matérias brutas oriundas do meio ambiente" (KARSAKLIN, p.47, 2014).

${ }^{5}$ Motivação (KARSAKLIN, p.23/24, 2014) "está relacionada ao equilíbrio psicológico do indivíduo, pois a descoberta de uma necessidade leva o indivíduo a uma situação de desconforto, por isso ele tem motivação suficiente para procurar uma solução que possibilite o retorno a seu estado de equilíbrio".

${ }^{6}$ Karasinski, Lucas. Qual a origem e o significado por trás do nome das principais tecnologias do mercado?TecMundo. 2009. <http://www.tecmundo.com.br/toshiba/2790-qual-a-origem-e-o-significado-por-tras-do-nome-das-principais-empresas-de-tecnologia-do-mercado-.htm>. Acesso em 14 jul. 2016.

${ }^{7}$ GIF - significa "GraphicsInterchangeFormat", é um formato de imagem muitoutilizado na web, geralmente uma animação de curta duração.

${ }^{8}$ Pereira, Leonardo. Usuários estão postando Gifs de filmes inteiros no Twitter. Olhar digital. 2016. <http://olhardigital.uol.com.br/noticia/usuarios-estao-postando-gifs-de-filmes-inteiros-no-Twitter/60211>. Acesso em 14 jul. 2016.

9 "Os Tweets Promovidos são Tweets pagos por nossos anunciantes. Eles aparecem na timeline de sua Página Inicial, acima dos resultados de busca no Twitter, e em outros lugares da plataforma e são visivelmente marcados como texto "Promovido"."(TWITTER, 2016, online).

${ }^{10}$ Twitter. 2016. <https://support.Twitter.com/articles/267266\#>. Acesso em 14 jul. 2016.

${ }^{11}$ Na pesquisa mencionada a revista Cosmopolitan Brasil ainda consta como "Nova", pois a alteração de título ocorreu em abril de 2015.

${ }^{12}$ O termo "pageviews", indica a quantidade de páginas que um usuário visita/acessa cada vez que entra no seu site ou rede social digital. 
${ }^{13}<$ https://twitter.com/revista_tpm>. Acesso em 29 mai 2016.

${ }^{14}<$ https://twitter.com/Cosmopolitan_br>. Acasso em 29 mai 2016.

${ }^{15}$ Refere-se a predefinição de dias da semana, dentro de determinado período, fechando um ciclo semanal, não sequencial, ou seja, cada dia da semana analisado será em semanas consecutivas distintas.

${ }^{16}<$ https://Twitter.com/revista_tpm/status/736970367567155203>. Acesso em 29 mai 2016.

${ }^{17}<$ https://Twitter.com/revista_tpm/status/739953902603382784>. Acesso em 06 jun 2016.

${ }^{18}<$ https://Twitter.com/revista_tpm/status/745751883084632064>. Acesso em 22 jun 2016.

${ }^{19}<$ https://Twitter.com/revista_tpm/status/754344966185324544>. Acesso em 16 jul 2016.

${ }^{20}<$ metametaoficial.com.br>. Acesso em 23 jun 2016.

${ }^{21}<$ https://twitter.com/Cosmopolitan_br/status/737040852480974849> Acesso em 29 mai 2016. e <https://twitter.com/Cosmopolitan_br/status/739940034485227521> Acesso em 06 jun 2016.

${ }^{22}<$ https://twitter.com/Cosmopolitan_br/status/739758774550827008>. Acesso 06 jun 2016. e <https://twitter.com/Cosmopolitan_br/status/745557003351658496>. Acesso 22 jun 2016.

${ }^{23}$ <https://Twitter.com/revista_tpm/status/742506931407839236>. Acesso em 14 um 2016.

${ }^{24}<$ https://Twitter.com/jornasxassedio/status/745671111984185344>Acesso em 22 jun 2016. 


\section{Taís Steffenello Ghisleni}

Possui Graduação em Comunicação Social - Publicidade e Propaganda pela Universidade Regional do Noroeste do Estado do Rio Grande do Sul, Especialização em Ciência do Movimento Humano - Laboratório de Comunicação, Movimento e Mídia pela Universidade Federal de Santa Maria ; e Mestrado em Engenharia de Produção pela Universidade Federal de Santa Maria (2005). Atualmente é professora no Centro Universitário Franciscano e Doutoranda em Comunicação Midiática (POSCOM - UFSM). Atua principalmente nos seguintes temas: estratégias de comunicação, comunicação e discurso organizacional online, ecologia das mídias e novas tecnologias.

E-mail: taisghisleni@yahoo.com.br

\section{Letícia Rodrigues Moreira}

Bacharel em Comunicação Social - Habilitação em Publicidade e Propaganda, graduada na UFSM; Técnica em Administração, pelo Colégio Politécnico da UFSM; e MBA em Mídias Sociais Digitais, pela UNIFRA.

E-mail: leticiar_moreira@yahoo.com.br 